\title{
Financial Sustainability of the Japanese Medical Payment System: Analysis of the Japanese Medical Expenditure for Educational Hospitalization of Patients with Type 2 Diabetes
}

\author{
Kazumitsu Nawata1, Koichi Kawabuchi² \\ ${ }^{1}$ Graduate School of Engineering, University of Tokyo, Tokyo, Japan \\ ${ }^{2}$ Graduate School of Medical and Dental Sciences, Tokyo Medical and Dental University, Tokyo, Japan \\ Email: nawata@tmi.t.u-tokyo.ac.jp, kawabuchi.hce@tmd.ac.jp
}

Received 27 July 2015; accepted 14 August 2015; published 17 August 2015

Copyright (C) 2015 by authors and Scientific Research Publishing Inc.

This work is licensed under the Creative Commons Attribution International License (CC BY).

http://creativecommons.org/licenses/by/4.0/

(c) (i) Open Access

\begin{abstract}
Japanese medical expenditures have increased rapidly in recent years and are predicted to continue rising. Indeed, it remains uncertain whether the current Japanese medical system can be sustained. In this paper, we analyzed the medical expenditures for educational hospitalization of patients with type 2 diabetes. A dataset of 6173 patients from 36 hospitals was used in the analysis. The sample period was from July 2008 to March 2012. We analyzed the medical expenditures in two ways. First, we analyzed the length of hospital stay (LOS). Next, we analyzed the daily expenditure per patient. The Box-Cox transformation model was used in the first analysis and the ordinary least squares method in the second. Comorbidities and complications prolonged LOS and increased daily expenditures. The LOS was significantly different among hospitals. On the other hand, the differences in daily expenditures among hospitals were relatively small, such that LOS was the main determinant of medical expenditures. Previous studies suggested that LOS could be shortened without degradation of medical quality. Moreover, LOS could be controlled by introducing proper critical paths and improving and standardizing educational programs. Hence, it would be possible to control the medical expenditures for this disease.
\end{abstract}

\section{Keywords}

Medical Expenditure, Financial Problem, Type 2 Diabetes Patients, Length of Stay (LOS), Educational Hospitalization, Daily Medical Expenditure, Box-Cox Transformation Model 


\section{Introduction}

Figure 1 shows the Japanese medical expenditures from the fiscal years (hereafter FY; the Japanese fiscal year starts in April and ends in March of the subsequent year, the abbreviations used in this paper were summarized in Appendix) 1985 to 2012 [1]. The Japanese total medical expenditures have been constantly increasing on the order of 3\% per year except for FY 2001-2006, when the medical payment system was reformed under the Koizumi Cabinet. As a result, the Japanese medical expenditures reached 39.2 trillion yen in FY 2012 and increased by 0.6 trillion yen from the previous FY. Since Japanese nominal Gross Domestic Product (GDP) did not increase over the last 20 years, the medical expenditure reached $8.3 \%$ of the GDP.

According to the World Health Organization (WHO) [2], the total health expenditures (which included not only medical but also other health expenditures) were 9.4\% of GDP in Australia, $10.9 \%$ in Canada, $11.6 \%$ in France, $11.3 \%$ in Germany, $10.3 \%$ in Japan, $9.3 \%$ in the United Kingdom, and $17.0 \%$ in the United States in 2012. The Japanese figure was thus not particularly large among major countries at this time. Figure 2 shows the Japanese population structure by age in 2013 [3]. The portion of the aged population is expected to increase in the future. The medical expenditure per person in FY 2012 was: younger than 65: 177 thousand yen; 65 or older: 717 thousand yen; 70 or older: 805 thousand yen; and 75 or older: 892 thousand yen [1]. Growing medical expenditures are now a worldwide concern, and numerous studies have been done to address this topic using various methods ([4]-[13] are examples of recent studies). However, the results and hypotheses of these studies lead to the same conclusion: namely, there is no doubt that the Japanese medical expenditure will increase rapidly in the future unless fundamental improvements are made to the medical system.

Japan instituted a mandatory public health insurance system in 1961, and since that time all Japanese have been required to join some type of public insurance. Currently, the medical expenditures paid by patients are $30 \%$ of their actual expenditures for individuals younger than 70 . On the other hand, the payments are $20 \%$ of

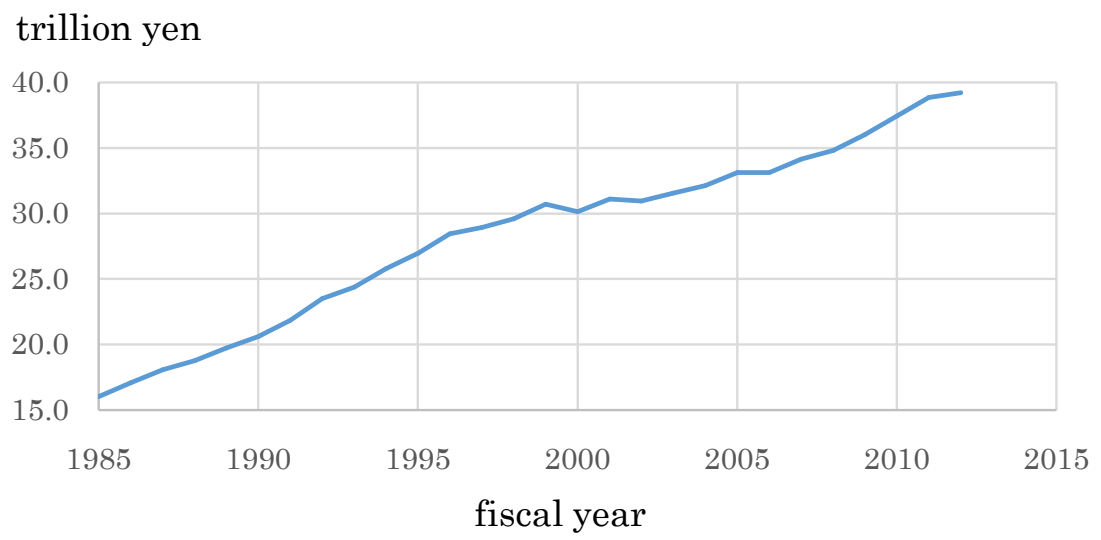

Figure 1. Japanese medical expenditures [1].

thousand

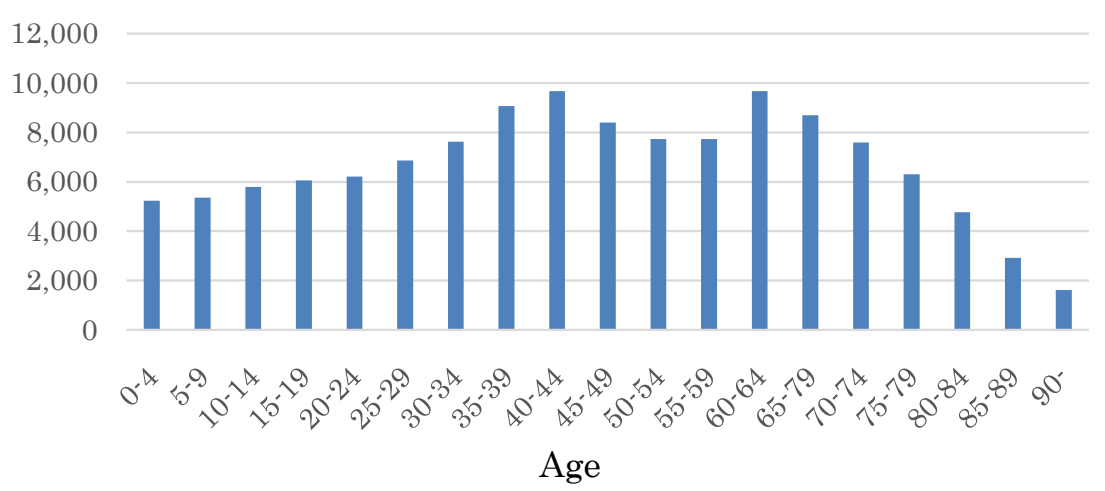

Figure 2. Distribution of Japanese popluation by age [2]. 
expenditures for those aged 70 - 74 (10\% by April, 2014) and 10\% of expenditures for those age 75 or older ${ }^{1}$. Moreover, monthly limits have been set for patients 70 or older: 12 thousand yen for outpatient services and 44.4 thousand yen for overall medical payments. As a result, the public expenditures and the total cost of health insurance premiums have reached 15.146 trillion and 19.120 trillion yen [1], respectively. Direct payments by patients accounted for only 4.619 trillion yen or 11.9\% of total medical expenditures in FY 2012. Hence the financial sustainability of the system is now a very serious question.

One of the best answers for the financial problem is to treat patients more efficiently and control expenditures without degradation of treatments. Longer length of hospital stay (LOS) is one of the most prominent characteristics of the Japanese medical system. According to the Organisation for Economic Cooperation and Development (OECD) [14], the average lengths of stay (ALOS) for all causes in 2011 were 5.8 days in Australia, 7.4 days in Canada, 5.6 days in France, 9.3 days in Germany, 7.7 days in Italy, 7 days in the United Kingdom, and 4.8 days in the United States (the US figure was for 2010). In Japan, however, the ALOS of hospitals was 32.0 days for all beds and 17.9 days for general beds [15]; clearly these durations were much longer than those of other major countries, which affected medical expenditures. Hence it might be possible to control the medical expenditures by reducing LOS.

Diabetes has become a very important disease both in medical and economic terms. The Japanese medical expenditure on diabetes in 2012 was 1209 billion yen [1]; diabetes was thus the third-most costly disease, after malignant tumor (cancer, 3327 billion yen) and renal insufficiency (1490 billion yen). The American Diabetes Association (ADA) estimated the total cost of diagnosed diabetes was estimated at \$245 billion in 2012 in the United States [16]. (The ADA [17] also reported various statistics of diabetes in the United States.) According to the OECD [18], the annual cost of diabetes prevention and treatment is approximately 90 billion euro in Europe alone. The International Diabetes Federation (IDF) [19] reported that the number of people with diabetes was 387 million in 2014, or 8.3\% of the world population, and was expected to increase by 205 million in 2035 . By regions, the numbers were 52 million in Europe, 37 million in the Middle East and North Africa, 25 million in North America and the Caribbean, 75 million in South-East Asia, and 128 million in the Western Pacific. The IDF also estimated costs per patient with diabetes as follows: \$7.931 in Australia; \$6741 in Canada; \$5600 in France; \$4944 in Germany; \$4908 in Japan; \$4666 in Italy; \$4466 in the United Kingdom; and \$10,902 in the United Sates. In Japan, the potential population with diabetes age 20 or over was estimated as $16.2 \%$ and $9.2 \%$ of the male and female population in 2013 [20].

Among all diabetes cases, 90\% or more are type 2 diabetes [21]. Although insulin is not produced in type 1 diabetes, the body does not use insulin properly in type 2 diabetes. The pancreas makes extra insulin at first, but it will eventually be unable to make enough insulin to keep the blood glucose levels normal. When glucose builds up in the blood, it can cause 1) cells may be starved for energy immediately, and ii) high blood glucose levels may hurt eyes, kidneys, nerves or hearts in a long time. Treatments of type 2 diabetes are lifestyle improvements, oral pills and insulin injections [22]. The AEA stated that "Stay at a healthy weight, eat well and be active. With these steps, you can stay healthier longer and lower your risk of diabetes” [23], and the risk of type 2 diabetes can be controlled and reduced.

In this paper, we analyze the medical expenditures applied to educational programs for improving the lifestyles of type 2 diabetes patients through dietetic treatments and kinesitherapy rather than direct medical treatments. Accordingly, the IDF has stated that "As the world prevalence of diabetes increases, efforts to promote diabetes self-management education are critical to reducing the human and economic burden of diabetes” [24]. For details of patient education, see ADA [25] and Diabetes UK [26]. However, despite the stated importance of diabetes education, there remains little awareness of this aspect of disease management. Mehrotra and Kim [27] have suggested that more money should be allocated to states to promote diabetes education, while Nelson et al. [28] demonstrated that rates of diabetes education were depended on insurance type in the United States.

Although the proper education for diabetes patients is very important, it must be done efficiently. In our dataset, $27.2 \%$ of total patients received educational hospitalization, and the medical expenditures of these patients accounted for $21.3 \%$ of total expenditures on diabetes. Hence improving educational hospitalization could have a significant impact on Japanese medical expenditures. Since the purpose of educational hospitalization is not to perform medical treatments, it is reasonable to consider that the educational programs could be standardized and the ALOS could be made similar among hospitals. Hospitals with larger ALOS would be able to reduce their

${ }^{1}$ For people age 70 or over, if their revenues exceed a certain standard amount (generally, the average monthly revenue from April to June is 280,000 yen), their payments become $30 \%$. 
LOS by modifying their clinical path and programs. Nawata and Kawabuchi [29] studied LOS for educational hospitalization for type 2 diabetes patients. They found that the ALOS of some hospitals was unreasonably long even after eliminating the influence of patient characteristics. However, their study had some important limitations. First, the sample period of July to December 2008 was relatively old, and the sample size was only 991 patients. Second, medical expenditures were not analyzed. Finally, the effects of PDC/PDPS ${ }^{2}$, the Japanese medical payment system that is revised every second year, could not be evaluated.

In this paper, we sought to overcome these limitations of the previous study. We used a dataset obtained from July 2008 to March 2012 that included 6173 type 2 diabetes patients without secondary diseases (DPC code 10070xxxxx0x) from 36 hospitals. We investigated the possibility of controlling medical expenditures without degrading the quality of medical treatments. Since the DPC/PDPS was revised in April 2010, the effect of the revision was also analyzed. All participating hospitals had at least 10 qualifying patients before and after the 2010 revision.

\section{Data and Changes in Hospital Payments after the 2010 DPC/PDPS Revision}

\subsection{Data}

The data used in this study were collected by the Department of Health Care Economics at the Tokyo Medical and Dental University from 103 hospitals. For details of the data, see Nawata and Kawabuchi [29]. The original dataset included 27,861 patients with an ALOS of 17.9 days. The data of medical expenditures for 206 were not available. The total and average medical expenditures were 13,401 million yen and 484,858 yen, respectively. Among these patients, 7854 were undergoing educational hospitalization with an ALOS of 14.0 days, and their total and average expenditures were 2861 million yen and 377,735 yen, respectively. The number of type 2 diabetes patients was 22,564. In our analysis, we considered LOS and medical expenditures only for educational hospitalization of type 2 diabetic patients whose DPC code was 100070xxxxxx0x. As in the previous study, we excluded data for patients treated in clinical departments that did not specialize in diabetes and data for patients whose principal diseases were not diabetes.

We also evaluated the effects of the DPC/PDPS revision in April 2010, and we used the data of 6173 patients who were not missing any values for the explanatory variables from 36 hospitals (Hp1-36) which had at least qualifying 10 patients both before and after the April 2010 revision. The medical expenditures were analyzed in two ways. First, the LOS was analyzed, and then the daily medical expenditure per patient (hereafter, daily expenditure) was analyzed. The LOS by hospital is shown in Table 1. The ALOS was 13.7 days for all patients. The minimum ALOS was 5.7 days (Hp17) and the maximum was 27.1 days (Hp3). The difference was 21.4 days and the maximum was 4.7 times as large as the minimum, indicating surprisingly large differences among hospitals. In the analysis of medical expenditures, we used data from 6162 patients after excluding the data of 11 patients due to an absence of medical expenditure data $(n=5)$, daily expenditures that were too low (below 10,000 yen per day; $n=5$ ), or daily expenditures that were unreasonably high compared to the LOS ( $n=1$; the injections cost as much as 1.5 million yen for this patient). The average medical expenditure per patient for all patients was 370,336 yen. The minimum was 164,351 yen and maximum was 665,226 yen; the difference was over 500,000 yen and the maximum was 4 times as large as minimum. As with the ALOS, there were large differences among hospitals.

\subsection{Changes in Hospital Payments after the 2010 DPC/PDPS Revision}

The DPC/PDPS has been revised every second year since 2004. During the sample period, the revision was done in April 2010. Before the revision (hereafter, first period), the per diem payment to hospitals determined by the DPC/PDPS was 2547 points for 1 - 7 days, 1924 points for 8 - 15 days, and 1635 points for 16 - 29 days. After the revision (hereafter, second period), it became 2480 points for 1 - 7 days, 1787 points for 8 - 15 days, and 1519 points for 16 - 29 days. Note that the hospitals are paid 10 yen for each point. The specific hospitalization

\footnotetext{
${ }^{2}$ In April 2003, Japan introduced a new medical inclusive payment system called the DPC/PDPS (diagnosis procedure combination/per diem payment system) and it has been extended to general hospitals since April 2004. The DPC/PDPS is revised every second year along with the revision of the medical payment system. As of April 2014, 1585 hospitals (21\% of general hospitals) with a total of 492,206 beds (55\% of all beds) joined the DPC/PDPS. The DPC/PDPS is a per diem inclusive payment system. A DPC code is assigned to each disease, and for each code three periods are specified (Period I, Period II and specific hospitalization period) along with standardized per diem payments for each period. The payments diminish with increasing LOS. For details, see Nawata et al. [43] and Nawata and Kawabuchi [29].
} 
Table 1. LOS and expenditure per patient by hospital.

\begin{tabular}{|c|c|c|c|c|c|}
\hline \multirow{2}{*}{ Hospital } & \multirow{2}{*}{ No. of patients } & \multicolumn{2}{|c|}{ LOS } & \multicolumn{2}{|c|}{ Expenditure per patient (yen) } \\
\hline & & ALOS & S.D. & Average & S.D. \\
\hline Hр1 & 46 & 12.72 & 4.18 & 355,164 & 106,432 \\
\hline Hp2 & 317 & 16.10 & 8.17 & 424,599 & 175,574 \\
\hline Нр3 & 182 & 27.21 & 8.94 & 635,129 & 195,020 \\
\hline Hр4 & 67 & 14.40 & 4.64 & 382,848 & 96,429 \\
\hline Hp5 & 48 & 10.79 & 2.06 & 310,286 & 47,952 \\
\hline Hp6 & 93 & 24.92 & 7.87 & 665,226 & 179,077 \\
\hline Hp7 & 74 & 16.07 & 11.25 & 430,240 & 251,101 \\
\hline Hр8 & 44 & 8.09 & 1.66 & 247,656 & 46,753 \\
\hline Нp9 & 76 & 11.86 & 4.99 & 330,150 & 119,887 \\
\hline Нp10 & 234 & 13.85 & 3.35 & 385,825 & 89,866 \\
\hline Hр11 & 187 & 15.27 & 3.60 & 397,583 & 81,628 \\
\hline Hp12 & 310 & 8.97 & 4.77 & 261,496 & 118,432 \\
\hline Нp13 & 183 & 15.61 & 4.59 & 394,621 & 94,444 \\
\hline Нp14 & 206 & 11.97 & 5.44 & 322,956 & 124,750 \\
\hline Hp15 & 73 & 9.33 & 5.57 & 258,458 & 126,146 \\
\hline Нp16 & 249 & 8.94 & 2.33 & 270,977 & 51,678 \\
\hline Hp17 & 46 & 5.74 & 5.09 & 164,351 & 139,192 \\
\hline Нp18 & 28 & 12.89 & 6.15 & 367,856 & 139,541 \\
\hline Нp19 & 57 & 13.42 & 8.24 & 341,236 & 176,671 \\
\hline Нр20 & 213 & 14.83 & 7.30 & 396,469 & 170,199 \\
\hline Нp21 & 229 & 9.97 & 2.37 & 295,153 & 72,032 \\
\hline Hр22 & 328 & 13.23 & 1.97 & 359,064 & 51,292 \\
\hline Нp23 & 154 & 13.85 & 7.66 & 378,323 & 180,775 \\
\hline Нp24 & 35 & 17.60 & 9.56 & 445,893 & 259,854 \\
\hline Нp25 & 74 & 7.65 & 5.08 & 212,281 & 127,784 \\
\hline Нp26 & 344 & 15.40 & 4.14 & 420,158 & 100,551 \\
\hline Нp27 & 63 & 21.56 & 10.00 & 549,841 & 312,260 \\
\hline Нр28 & 130 & 12.14 & 6.79 & 321,558 & 162,173 \\
\hline Нр29 & 54 & 13.28 & 8.51 & 343,983 & 179,591 \\
\hline Нр30 & 280 & 16.83 & 6.65 & 427,590 & 136,179 \\
\hline Нр31 & 228 & 9.27 & 3.32 & 269,489 & 82,493 \\
\hline Нp32 & 185 & 13.11 & 3.50 & 353,373 & 81,223 \\
\hline Нр33 & 199 & 13.90 & 0.98 & 410,102 & 41,474 \\
\hline Нp34 & 1013 & 12.98 & 5.11 & 362,486 & 122,418 \\
\hline Нp35 & 81 & 16.15 & 6.01 & 406,274 & 129,104 \\
\hline Нр36 & 43 & 11.95 & 3.83 & 326,675 & 84,819 \\
\hline All & 6173 & 13.68 & 6.65 & 370,352 & 152,902 \\
\hline
\end{tabular}

S.D.: Standard deviation. 
period was 29 days for this DPC code and after 29 days, the payments reverted to the conventional pay-for-service system. The reductions per diem payments were $1.5 \%$ in the first 7 days but about $7 \%$ after that.

\section{Analyses of LOS and Daily Expenditure}

In this section, we analyze the medical expenditure. Two types of analyses were performed. First, the LOS was analyzed, and then the daily expenditure.

\subsection{Analysis of LOS}

Figure 3 shows the distribution of LOS of patients. The distribution shows a heavy tail on the right side, and thus we considered that the ordinary least squares (OLS) method might not suitable for analyzing this dataset. Therefore, as in the previous study [29], we used the Box-Cox transformation (BC) model [30] given as

$$
\begin{aligned}
& z_{t}=\left\{\begin{array}{l}
\frac{y_{t}^{\lambda}-1}{\lambda}, \quad \text { if } \lambda \neq 0, \\
\log \left(y_{t}\right), \quad \text { if } \lambda=0,
\end{array}\right. \\
& z_{t}=x_{t}^{\prime} \beta+u_{t}, \quad y_{t} \geq 0, t=1,2, \cdots, T,
\end{aligned}
$$

where $y_{t}$ is LOS, $\lambda$ is the transformation parameter, and $x_{t}$ and $\beta$ are the $k$-th dimensional vectors of the explanatory variables and coefficients, respectively. The variables used as explanatory variables are given in Table 2. Female and Age dummies expressed the basic patient characteristics. The base of the age dummies was

\begin{tabular}{|c|c|c|}
\hline Variable & Definition & Summary of 6173 patients \\
\hline Female & Dummy variable: 1 , female; 0 , male & $1: 2450$ \\
\hline Age $60-64$ & Dummy variable: 1 , age 60 - 64; 0 : otherwise & 1: 1056 \\
\hline Age $65-69$ & Dummy variable: 1 , age 65 - 69; 0 , otherwise & 1: 905 \\
\hline Age $70-74$ & Dummy variable: 1 , age $70-74 ; 0$, otherwise & 1: 764 \\
\hline Age 75 & Dummy variable: 1 , age 75 or over; 0 , otherwise & 1: 910 \\
\hline Comorbidities & Number of comorbidities & $\begin{array}{c}0: 827 ; 1: 910 ; 2: 1003 ; \\
\text { 3: 923; 4: } 2511\end{array}$ \\
\hline Complications & Number of complications & $\begin{array}{c}0: 3838 ; 1: 1085 ; 2: 564 \\
\text { 3: 339; } 4: 348\end{array}$ \\
\hline Acute hospitalization & Dummy variable: 1 , acute hospitalization; 0 , otherwise & 1: 183 \\
\hline Another hospital & Dummy variable: 1 , introduced by other hospitals; 0 , otherwise & 1: 2915 \\
\hline Own outpatient & Dummy variable: 1 , own outpatient; 0 , otherwise & $1: 5282$ \\
\hline Discharged place & Dummy variable: 1 , discharged to another hospital or facility; 0 , otherwise & 1: 1445 \\
\hline Day 8 dummy & Dummy variable: 1 , LOS is 8 days; 0 , otherwise & $1: 547$ \\
\hline Day 30 dummy & Dummy variable: 1 , LOS is over 29 days; 0 , otherwise & 1: 198 \\
\hline Second period & Dummy variable: 1, after April 2010; 0, otherwise & $1: 3198$ \\
\hline \multicolumn{3}{|l|}{ ICD10 dummies } \\
\hline E11.2 & 1: E11.2 (with kidney complications); 0: otherwise & $1: 266$ \\
\hline E11.3 & 1: E11.3 (with ophthalmic complications); 0: otherwise & 1: 420 \\
\hline E11.4 & 1: E11.4 (with neurological complications); 0: otherwise & 1: 505 \\
\hline E11.5 & 1: E11.5 (with circulatory complications); 0: otherwise & $1: 50$ \\
\hline E11.6 & 1: E11.6 (with other specified complications); 0: otherwise & 1: 1019 \\
\hline E11.7 & 1: E11.7 (with multiple complications); 0: otherwise & 1: 1801 \\
\hline \multicolumn{3}{|l|}{ Hospital dummies } \\
\hline Hp $i$ & 1:Hospital $i ; 0$ : otherwise & \\
\hline
\end{tabular}

\section{Table 2. Explanatory variables.}




\section{number of patients}

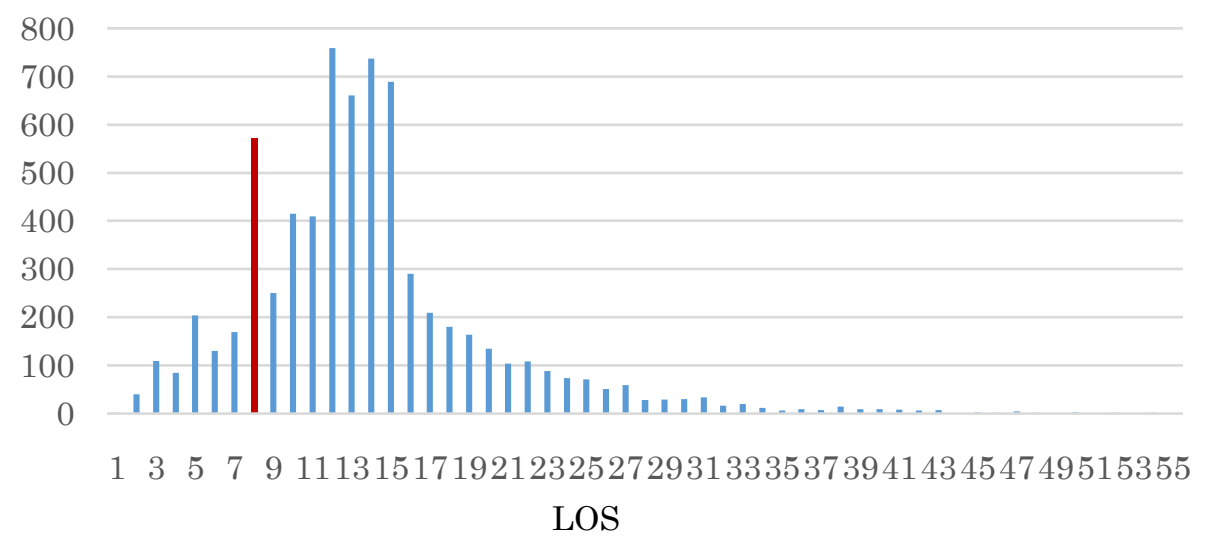

Figure 3. Distribution of LOS.

age under 60. Comorbidities, Complications, Acute Hospitalization, Another Hospital, Own Outpatient, and Discharged Place (to another hospital or facility) dummies were used to describe the conditions of patients. Since LOS peaked at eight days, a Day 8 dummy was also added. If the LOS exceeds the specific hospitalization period (29 days), payments to hospitals revert to the conventional fee-for-service system. We therefore added a Day 30 dummy. We also used a Second Period dummy to evaluate the effect of the 2010 DPC/PDPS revision. The ICD-10 (International Classification of Diseases version 10) dummies based on E11.9 (diabetes without complications) were used to denote types of diabetic. To evaluate the effect of the individual hospitals, 36 hospital dummies were used and the constant term was not included in the model. These dummies were valued at 1 if a patient was in hospital $i$ and 0 otherwise. To evaluate the direct effects of hospitals, a constant term was not used.

As a result, $x_{t}^{\prime} \beta$ of Equation (1) becomes

$$
\begin{aligned}
x_{t}^{\prime} \beta= & \beta_{1} \text { Female }+\beta_{2} \text { Age } 60-64+\beta_{3} \text { Age } 65-69+\beta_{4} \text { Age } 70-74 \\
& +\beta_{5} \text { Age } 75+\beta_{6} \text { Comorbidities }+\beta_{7} \text { Complications }+\beta_{8} \text { Acute Hospitalization } \\
& +\beta_{9} \text { Another Hospital }+\beta_{10} \text { Own Outpatient }+\beta_{11} \text { Discharged Place }+\beta_{12} \text { Day } 8 \\
& +\beta_{13} \text { Day } 30+\beta_{14} \text { Second Period }+\sum_{\ell} \beta_{\ell} \ell \text {-th ICD-10 Classification Dummy } \\
& +\sum_{i} \beta_{i} \text { Hospital } i \text { Dummy. }
\end{aligned}
$$

For the estimation of the model, the maximum likelihood estimator under the normality assumption (BC MLE) is generally used. However, two assumptions are necessary to use the BC MLE: 1) the assumption of "small $\sigma$ " [31] and 2) the assumption of homoscedasticity of error terms. For the tests of these assumptions, two estimators proposed by Nawata [32] [33] were used in addition to the BC MLE. Let $\hat{\lambda}_{B C}, \hat{\lambda}_{N}$ and $\hat{\lambda}_{R}$ be the BC MLE and Nawata's estimators. Since values of $\beta$ and $\sigma$ are obtained by the OLS when $\lambda$ is given, we can easily calculate the estimators by the scanning method for all three cases [32] [33]. The statistical software EViews 7 was used in the estimation. The results were $\hat{\lambda}_{B C}=0.565, \hat{\lambda}_{N}=0.549$ and $\hat{\lambda}_{R}=0.556$. The $t$-values for the first and second tests are $t_{1}=\left(\hat{\lambda}_{B C}-\hat{\lambda}_{N}\right) / \sqrt{V\left(\hat{\lambda}_{B C}-\hat{\lambda}_{N}\right)}=1.735$ and $t_{2}=\left(\hat{\lambda}_{B C}-\hat{\lambda}_{R}\right) / \sqrt{V\left(\hat{\lambda}_{B C}-\hat{\lambda}_{R}\right)}=1.436$, respectively, and both of them are accepted at a significance level of 5\%; this indicates that the BC MLE can be used in the analysis. The variances were calculated by the formulas obtained by Nawata and Kawabuchi [29]. Unlike in the previous study, the exact asymptotic variances were estimated in the second test. The variances were calculated by the matrix language of EViews 7 .

The results of the BC MLE are shown in Table 3. The $t$-values of Comorbidities and Complications were positive and very large; they were significant at the $1 \%$ level, indicating that comorbidities and complications made LOS longer, as in the previous study. The dummies for Acute Hospitalization and Another Hospital were 
Table 3. Results of estimation (LOS).

\begin{tabular}{|c|c|c|c|c|c|c|c|}
\hline Variable & Estimates & S. E. & $t$-value & Variable & Estimates & S. E. & $t$-value \\
\hline$\lambda$ & 0.5652 & 0.0044 & $127.4696^{* *}$ & \multicolumn{4}{|c|}{ Hospital dummies } \\
\hline Female & 0.0574 & 0.0349 & 1.6433 & Нp8 & 4.0945 & 0.1954 & $20.9572^{* *}$ \\
\hline Age 60 - 64 & -0.0330 & 0.0466 & -0.7096 & Hр9 & 4.8192 & 0.2027 & $23.7710^{* *}$ \\
\hline Age $65-69$ & -0.0186 & 0.0496 & -0.3749 & Нp10 & 5.3379 & 0.1331 & $40.0905^{* *}$ \\
\hline Age $70-74$ & 0.1177 & 0.1261 & 0.9334 & Hp11 & 5.6009 & 0.1331 & $42.0671^{* *}$ \\
\hline Age 75 & 0.1061 & 0.1163 & 0.9122 & Hp12 & 3.8866 & 0.1445 & $26.8924^{* *}$ \\
\hline Comorbidities & 0.1527 & 0.0138 & $11.0270^{* *}$ & Нp13 & 5.9207 & 0.1314 & $45.0490^{* *}$ \\
\hline Complications & 0.1970 & 0.0160 & $12.3447^{* *}$ & Нp14 & 4.7258 & 0.1461 & $32.3463^{* *}$ \\
\hline Acute hospitalization & 0.6345 & 0.1214 & $5.2278^{* *}$ & Hp15 & 3.6170 & 0.2136 & $16.9328^{* * *}$ \\
\hline Another hospital & 0.0884 & 0.0379 & $2.3318^{*}$ & Hp16 & 4.4866 & 0.1356 & $33.0820^{* *}$ \\
\hline Own outpatient & -0.0243 & 0.1040 & -0.2335 & Нp17 & 2.4263 & 0.3024 & $8.0226^{* *}$ \\
\hline Discharged place & -0.0750 & 0.0441 & -1.7031 & Hp18 & 4.8877 & 0.3212 & $15.2188^{* *}$ \\
\hline Day 8 & -1.1402 & 0.0584 & $-19.5097^{* *}$ & Нp19 & 5.3523 & 0.2246 & $23.8255^{* *}$ \\
\hline Day 30 & 4.6552 & 0.1377 & $33.8105^{* *}$ & Нp20 & 5.2849 & 0.1572 & $33.6291^{* *}$ \\
\hline Second period & -0.0768 & 0.0348 & $-2.2091^{*}$ & Нр21 & 3.7349 & 0.1332 & $28.0326^{* *}$ \\
\hline ICD10 dummies & & & & Нp22 & 5.0837 & 0.1237 & $41.1099^{* *}$ \\
\hline E11.2 & 0.2241 & 0.0986 & $2.2726^{*}$ & Нр23 & 5.3831 & 0.1987 & $27.0891^{* *}$ \\
\hline E11.3 & 0.1079 & 0.0712 & 1.5163 & Нр24 & 5.6278 & 0.3265 & $17.2364^{* * *}$ \\
\hline E11.4 & 0.1499 & 0.0664 & $2.2592^{*}$ & Нp25 & 3.0847 & 0.2450 & $12.5884^{* *}$ \\
\hline E11.5 & 0.0451 & 0.1742 & 0.2591 & Нp26 & 5.7676 & 0.1277 & $45.1775^{* *}$ \\
\hline E11.6 & 0.2188 & 0.0618 & $3.5418^{* *}$ & Нр27 & 6.2866 & 0.2313 & $27.1833^{* * *}$ \\
\hline E11.7 & 0.3040 & 0.0475 & $6.3963^{* *}$ & Нр28 & 4.2702 & 0.2444 & $17.4741^{* *}$ \\
\hline Hospital dummies & & & & Нр29 & 4.2055 & 0.2564 & $16.3999^{* * *}$ \\
\hline Hp1 & 4.9829 & 0.2095 & $23.7904^{* *}$ & Нр30 & 5.8179 & 0.1373 & $42.3709^{* *}$ \\
\hline Hp2 & 5.5851 & 0.1537 & $36.3292^{* *}$ & Нp31 & 3.8849 & 0.1309 & $29.6692^{* *}$ \\
\hline Hр3 & 7.0499 & 0.1689 & $41.7509^{* *}$ & Нp32 & 5.1373 & 0.1261 & $40.7327^{* *}$ \\
\hline Hр4 & 5.2477 & 0.2641 & $19.8688^{* *}$ & Нр33 & 5.1394 & 0.1237 & $41.5337^{* *}$ \\
\hline Hp5 & 4.4280 & 0.1392 & $31.8043^{* *}$ & Нр34 & 4.8236 & 0.1233 & $39.1227^{* * *}$ \\
\hline Hp6 & 6.8958 & 0.1728 & $39.9092^{* *}$ & Нр35 & 5.4926 & 0.2077 & $26.4488^{* * *}$ \\
\hline Hp7 & 5.6841 & 0.2297 & $24.7424^{* *}$ & Нp36 & 4.9983 & 0.2063 & $24.2338^{* *}$ \\
\hline $\log L$ & & -17251.94 & & $\mathrm{R}^{2}$ & & 0.5556 & \\
\hline
\end{tabular}

S.E.: Standard error, ${ }^{*}$ Significant at the $5 \%$ level, ${ }^{* *}$ Significant at the $1 \%$ level.

positive and significant at the $1 \%$ and $5 \%$ level; however, those for Own Outpatient and Discharged Place were not significant at the $5 \%$ level. The former two variables prolonged LOS but the latter two variables did not. The Day 8 and Day 30 dummies were significant at the 1\% level. This indicates that one-week hospitalization and the specific hospitalization period affected the discharge decisions of hospitals. The estimate of the Second Period dummy was negative and significant at the $5 \%$ level, indicating that the 2010 revision reduced LOS. As for 
the ICD-10 dummies, E11.2, E11.4, and E11.7 were positive and significant at both the 5\% and 1\% levels. It is concluded that ophthalmic, neurological complications and multiple complications prolonged LOS but not other types of complications.

For the hospital dummies, the maximum estimate was 7.050 for $\mathrm{Hp} 3$, the minimum was 2.426 for $\mathrm{Hp} 17$ and the difference was 4.624; the influences was surprisingly larger than the effects of other variables. The correlation coefficient between ALOS and estimates of the hospital dummies was 0.922, and an almost linear relationship existed between these two variables. In other words, LOS was mainly determined by hospitals and patient characteristics and types of principle diseases had minor influences.

\subsection{Analysis of Daily Expenditure}

The results of the previous section showed that there were surprisingly large differences in ALOS among hospitals. In this section, we analyzed the distribution of daily expenditures for our patients. Figure 4 shows the distribution of daily expenditures. Since the distribution did not exhibit any heavy tails, the OLS method was used in the analysis. The daily expenditure $d_{t}$ was analyzed by the regression model as follows:

$$
\begin{aligned}
d_{t}= & \beta_{1} \text { LOS }+\beta_{2} \text { Female }+\beta_{3} \text { Age } 60-64+\beta_{4} \text { Age } 65-69+\beta_{5} \text { Age } 70-74 \\
& +\beta_{6} \text { Age } 75+\beta_{7} \text { Comorbidities }+\beta_{8} \text { Complications }+\beta_{9} \text { Acute Hospitalization } \\
& +\beta_{10} \text { Another Hospital }+\beta_{11} \text { Own Outpatient }+\beta_{12} \text { Discharged Place } \\
& +\beta_{13} \text { Day } 8+\beta_{14} \text { Day } 30+\beta_{15} \text { Day } 30 *(\text { LOS }-29)+\beta_{16} \text { Second Period } \\
& +\sum_{\ell} \beta_{\ell} \ell \text {-th ICD-10 Classification Dummy }+\sum_{i} \beta_{i} \text { Hospital } i \text { Dummy. }
\end{aligned}
$$

Before the specific hospitalization period, the daily payment to hospitals per patient gradually declined as the LOS became longer. However, the payment did not decrease after the specific hospitalization period. Therefore, Day 30 and Day 30*(LOS-29) were added as explanatory variables. The other explanatory variables were the same as in the previous case. The results of the estimation are given in Table 4.

The estimate of LOS was negative and significant at the $1 \%$ level; this was consistent with the DPC/PDPS, which stipulates that the daily payment decreases up to the specific hospitalization period. The effects of Gender and Age dummies were not significant and the effects of these variables were not admitted. Estimates of Comorbidities, Complications and Acute Hospitalization were positive and significant at the $1 \%$ level. The effect of Acute Hospitalization (2022 yen) was considered a particularly important factor. The estimate of Another Hospital dummy was not significant at the $5 \%$ level but the estimates for the dummies of Own Outpatient and Discharged Place were negative and significant at the 5\% and 1\% level. Estimates of Day 30 and Day 30*(LOS-29) were positive and significant at the $1 \%$ level. The coefficient of LOS after the specific sample period is the sum of estimates of LOS and Day 30*(LOS-29) and it became just -30 yen. This means the hospital's income did not decrease if the LOS exceeded the specific hospitalization period. The Second Period dummy was negative and significant at the $1 \%$ the level and it is concluded that the 2010 revision reduced the daily expenditure by 1585 yen. The maximum and minimum estimates of the hospital dummies were 35,512 (Hp6) and 31,836 (Hp25).

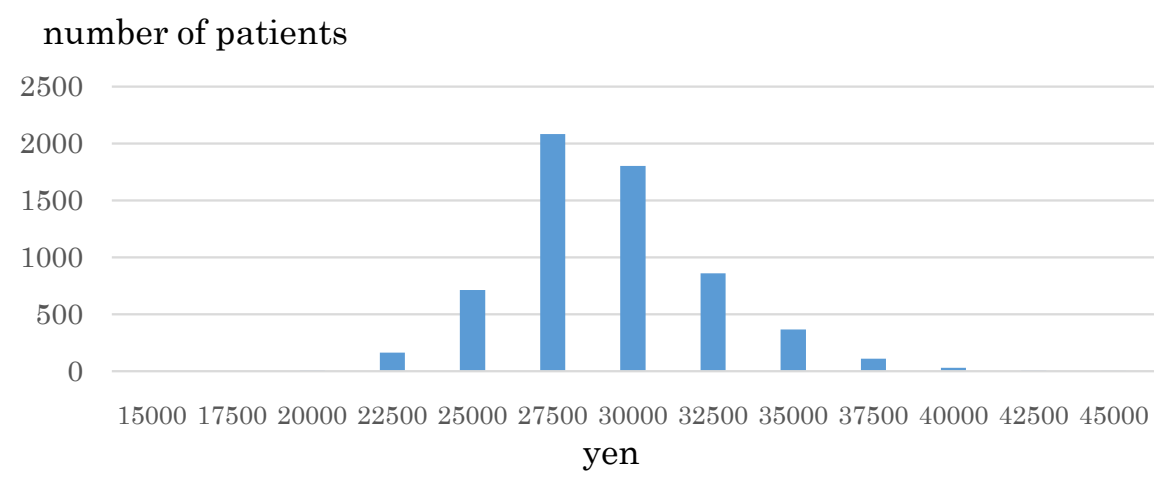

Figure 4. Distribution of daily expenditures per person. 
Table 4. Results of estimation (daily expenditure per patient).

\begin{tabular}{|c|c|c|c|c|c|c|c|}
\hline Variable & Estimates & S. E. & $t$-value & Variable & Estimates & S. E. & $t$-value \\
\hline LOS & -382.2 & 7.1 & $-54.1567^{* *}$ & \multicolumn{4}{|c|}{ Hospital dummies } \\
\hline Female & 16.0 & 58.5 & 0.2744 & Hр8 & 33,838 & 380 & $88.9342^{* *}$ \\
\hline Age 60 - 64 & 24.9 & 78.8 & 0.3163 & Hр9 & 33,651 & 303 & $110.8768^{* *}$ \\
\hline Age 65 - 69 & -9.1 & 83.8 & -0.1091 & Hp10 & 33,568 & 241 & $139.4941^{* *}$ \\
\hline Age $70-74$ & -282.2 & 200.9 & -1.4050 & Hp11 & 32,360 & 252 & $128.2448^{* *}$ \\
\hline Age 75 & 331.2 & 188.7 & 1.7546 & Hp12 & 33,831 & 218 & $155.0986^{* *}$ \\
\hline Comorbidities & 237.6 & 21.7 & $10.9635^{* *}$ & Нp13 & 32,382 & 251 & $128.8275^{* *}$ \\
\hline Complications & 95.4 & 26.4 & $3.6178^{* *}$ & Нp14 & 32,577 & 236 & $137.7778^{* *}$ \\
\hline Acute hospitalization & 2021.8 & 176.9 & $11.4295^{* *}$ & Hp15 & 32,479 & 316 & $102.9276^{* *}$ \\
\hline Another hospital & -55.2 & 65.0 & -0.8484 & Hр16 & 35,068 & 230 & $152.4231^{* *}$ \\
\hline Own outpatient & -389.9 & 147.7 & $-2.6402^{*}$ & Hр17 & 33,985 & 378 & $89.9444^{* *}$ \\
\hline Discharged place & -338.5 & 76.9 & $-4.4033^{* *}$ & Нp18 & 34,163 & 474 & $72.1151^{* *}$ \\
\hline Day 30 & 915.1 & 249.2 & $3.6726^{* *}$ & Нp19 & 32,172 & 313 & $102.6514^{* *}$ \\
\hline Day 30*(LOS-29) & 350.8 & 20.7 & $16.9562^{* *}$ & Нp20 & 33,019 & 240 & $137.5454^{* *}$ \\
\hline Second period & -1585.4 & 58.7 & $-27.0100^{* *}$ & Нp21 & 33,138 & 233 & $141.9228^{* *}$ \\
\hline ICD10 dummies & & & & Hр22 & 32,426 & 230 & $140.7383^{* *}$ \\
\hline E11.2 & 249.1 & 148.1 & 1.6814 & Нp23 & 33,988 & 251 & $135.4767^{* *}$ \\
\hline E11.3 & 196.2 & 121.4 & 1.6165 & Нp24 & 33,125 & 425 & $77.9534^{* *}$ \\
\hline E11.4 & 84.1 & 115.3 & 0.7291 & Нp25 & 31,836 & 306 & $104.0399^{* *}$ \\
\hline E11.5 & -250.2 & 321.8 & -0.7774 & Нp26 & 33,698 & 230 & $146.5429^{* *}$ \\
\hline E11.6 & 474.7 & 98.7 & $4.8114^{* *}$ & Нp27 & 32,039 & 345 & $92.8630^{* *}$ \\
\hline E11.7 & 565.7 & 78.7 & $7.1851^{* *}$ & Нp28 & 33,438 & 265 & $126.3027^{* *}$ \\
\hline Hospital dummies & & & & Нp29 & 32,249 & 349 & $92.4456^{* *}$ \\
\hline Hр1 & 33,105 & 373 & $88.6757^{* *}$ & Нр30 & 32,683 & 236 & $138.1977^{* *}$ \\
\hline Нр2 & 33,521 & 230 & $145.7176^{* *}$ & Нp31 & 33,269 & 222 & $150.0635^{* *}$ \\
\hline Нр3 & 32,970 & 271 & $121.8070^{* *}$ & Нp32 & 32,503 & 245 & $132.4883^{* *}$ \\
\hline Нp4 & 32,520 & 332 & $97.9824^{* *}$ & Нр33 & 35,072 & 252 & $139.0921^{* *}$ \\
\hline Hр5 & 33,589 & 339 & $99.1303^{* *}$ & Нp34 & 33,759 & 200 & $169.0791^{* *}$ \\
\hline Нp6 & 35,512 & 305 & $116.4777^{* *}$ & Hр35 & 32,458 & 314 & $103.3087^{* *}$ \\
\hline Hр7 & 33,443 & 318 & $105.1158^{* *}$ & Нр36 & 32,867 & 383 & $85.9060^{* *}$ \\
\hline $\mathrm{R}^{2}$ & & & & 0.5302 & & & \\
\hline
\end{tabular}

S.E.: Standard error; "Significant at the $5 \%$ level; ${ }^{* *}$ Significant at the $1 \%$ level.

\section{Discussion}

The OECD [18] states that "With health budgets already under great pressure and national budgets severely strained... we must find ways to prevent and manage diabetes in a cost-effective manner.” In keeping with this statement, we believe that the efficiency of medical treatments must be considered as a possible means of con- 
trolling medical expenditures in future Japanese medical policies. Since the BC model involves a non-linear transformation, we calculated ALOS in the first and second periods for a 60-year-old male patient who had three comorbidities and a single complications, was a normal (not acute hospitalization) outpatient without introduction from another hospital, returned home, and had an ICD-10 classification of E11.9 by hospitals. The results are given in Table 5. The maximum and minimum of ALOS were 20.3 (Hp3) and 6.6 (Hp17) days in the first period, and 20.2 days and 6.6 days in the second period. The difference was nearly 14 days and the maximum was 3.1 times as large as the minimum in both periods. This indicates that even after eliminating the influences of the patient characteristics and principle diseases, there were surprisingly large differences among hospitals. On the other hand, the largest difference in daily average expenditures among hospitals was 3676 yen or $13 \%$ of the average daily expenditure of all patients (27,971 yen); this value was much smaller than that of ALOS. Unlike Sato and Fushimi [34], we found that large differences of medical expenditures per patient were mainly caused by the LOS. Moreover, although the 2010 revision reduced daily expenditure by $5.7 \%$, the ALOS was shortened by less than 0.1 day or $1 \%$ of ALOS in most hospitals. In other words, the 2010 revision had a considerably large effect on the daily expenditure but a very small effect on ALOS, unlike in the United States [35].

The large differences of ALOS are accepted only if a long LOS will sufficiently improve the conditions of patients. However, Nagashima et al. [36] reported that there were no differences in the effects of educational hospitalization between four-day (three-night) and two-week stays. Yamamoto, Takeuchi and Ichikawa [37] reported that 1) the ALOS was shortened from 25.2 days to 14.6 days, 2) cooperation among medical staff became

Table 5. Estimated ALOS by hospitals*.

\begin{tabular}{|c|c|c|c|c|c|c|c|c|c|}
\hline \multirow{2}{*}{ Hospital } & \multicolumn{2}{|c|}{ Periods } & \multirow{2}{*}{ Difference } & \multirow{2}{*}{$\begin{array}{l}\text { Percent } \\
\text { changed }\end{array}$} & \multirow{2}{*}{ Hospital } & \multicolumn{2}{|c|}{ Periods } & \multirow{2}{*}{ Difference } & \multirow{2}{*}{$\begin{array}{l}\text { Percent } \\
\text { changed }\end{array}$} \\
\hline & First & Second & & & & First & Second & & \\
\hline Hp1 & 12.98 & 12.91 & 0.07 & $0.52 \%$ & Нp19 & 14.06 & 13.98 & 0.07 & $0.52 \%$ \\
\hline Hp2 & 14.78 & 14.71 & 0.08 & $0.52 \%$ & Нр20 & 13.85 & 13.78 & 0.07 & $0.52 \%$ \\
\hline Нp3 & 20.28 & 20.17 & 0.11 & $0.53 \%$ & Нр21 & 9.79 & 9.73 & 0.06 & $0.61 \%$ \\
\hline Нp4 & 13.74 & 13.67 & 0.07 & $0.52 \%$ & Нp22 & 13.27 & 13.20 & 0.07 & $0.52 \%$ \\
\hline Hp5 & 11.51 & 11.45 & 0.06 & $0.54 \%$ & Нр23 & 14.15 & 14.08 & 0.07 & $0.52 \%$ \\
\hline Hp6 & 19.61 & 19.51 & 0.10 & $0.52 \%$ & Нp24 & 14.92 & 14.84 & 0.08 & $0.52 \%$ \\
\hline Hp7 & 15.10 & 15.02 & 0.08 & $0.52 \%$ & Нp25 & 8.19 & 8.13 & 0.06 & $0.73 \%$ \\
\hline Нp8 & 10.67 & 10.61 & 0.06 & $0.56 \%$ & Нр26 & 15.38 & 15.30 & 0.08 & $0.52 \%$ \\
\hline Hр9 & 12.53 & 12.47 & 0.07 & $0.52 \%$ & Нр27 & 17.20 & 17.11 & 0.09 & $0.52 \%$ \\
\hline Hр10 & 14.01 & 13.94 & 0.07 & $0.52 \%$ & Нр28 & 11.11 & 11.05 & 0.06 & $0.55 \%$ \\
\hline Hp11 & 14.83 & 14.76 & 0.08 & $0.52 \%$ & Нр29 & 10.95 & 10.89 & 0.06 & $0.55 \%$ \\
\hline Hp12 & 10.16 & 10.10 & 0.06 & $0.59 \%$ & Нр30 & 15.55 & 15.47 & 0.08 & $0.52 \%$ \\
\hline Нp13 & 15.90 & 15.81 & 0.08 & $0.52 \%$ & Нp31 & 10.16 & 10.10 & 0.06 & $0.59 \%$ \\
\hline Hp14 & 12.28 & 12.22 & 0.06 & $0.52 \%$ & Нp32 & 13.42 & 13.35 & 0.07 & $0.52 \%$ \\
\hline Hр15 & 9.50 & 9.44 & 0.06 & $0.63 \%$ & Нр33 & 13.43 & 13.36 & 0.07 & $0.52 \%$ \\
\hline Нp16 & 11.66 & 11.60 & 0.06 & $0.53 \%$ & Нp34 & 12.54 & 12.48 & 0.07 & $0.52 \%$ \\
\hline Hр17 & 6.62 & 6.56 & 0.06 & $0.83 \%$ & Нp35 & 14.49 & 14.41 & 0.08 & $0.52 \%$ \\
\hline Hp18 & 12.72 & 12.65 & 0.07 & $0.52 \%$ & Нp36 & 13.02 & 12.96 & 0.07 & $0.52 \%$ \\
\hline
\end{tabular}

*ALOS of a 60-year-old male patient who had three comorbidities and a single complications, was a normal (not acute hospitalization) outpatient without introduction from another hospital, returned home, and had an ICD-10 classification of E11.9. 
easier, and iii) the scores of comprehensive tests were improved by the introduction of a critical path and standardization of educational programs. Kobori et al. [38] reported that ALOS was shortened from 14 days to 10 days by changing from a paper-based to a computerized critical path with similar outcomes. Tsurumi [39] reported that introduction of a critical path and standardization of treatments made cooperation among medical staff easier and improved understanding of diabetes and fasting therapy blood sugar tests. No studies showed benefits of long (such as two weeks or more) LOS in educational hospitalization.

As mentioned earlier, the major goal of this study was to evaluate whether we can possibly control medical expenditures without degrading the quality of medical treatments. In the case of this disease, the answer seems to be yes: medical expenditures for educational hospitalization could be reduced significantly by reducing LOS without degrading the effects of hospitalization. The total medical expenditures for diabetes hospitalization in Japan were 320 billion yen in FY 2012 [1]. Our dataset shows that 21\% of these expenditures went to educational hospitalization, and the analysis revealed that the medical expenditures for educational hospitalization were mainly determined by the LOS. Therefore, if we could reduce the ALOS by half (from 14 to 7 days), we would be able to reduce the medical expenditures by more than 30 billion yen. For that purpose, 1) introduction of critical path, and 2) improvement and standardization of educational programs including accountability and quality of trainers [40] are important, especially for hospitals with a long ALOS. The patient-centered diabetes care and education currently practiced in the United Kingdom [41] [42] might be a good example of such modifications. Reducing ALOS (and improving educational programs) can also benefit patients. A shorter ALOS reduces costs of hospitalization (including opportunity costs) for patients, and more (potential) patients can join educational programs if costs are reduced. As pointed out earlier, the risk of type 2 diabetes can be controlled through lifestyle improvements. Incentives to improve the efficiency of hospitals must be considered in the future revision of the medical payment system.

\section{Conclusions}

In this paper, we analyzed the LOS and daily medical expenditures using the data of 6173 patients at 36 hospitals In addition to the numbers of comorbidities and complications, the variables that affected the LOS were Acute Hospitalization, Another Hospital, Day 8, Day 30, and Second Period, (IDC-10) E11.2, E11.4, E11.6 and E11.7 dummies. Although the 2010 revision reduced the LOS, its effect was rather small—less than 0.1 day or $1 \%$ of ALOS in most hospitals. We found that there were very large differences in ALOS among hospitals even after eliminating the influences of the patient characteristics and principle diseases.

We then analyzed the daily expenditures. The estimate of LOS was negative and significant and daily expenditure declined with increasing LOS before the end of the specific hospitalization period. The numbers of comorbidities and complications also affected the daily expenditures. Other variables affecting the daily expenditures were Acute Hospitalization, Own Outpatient, Discharged Place, Day 30, Second Period, E11.6 and E11.7 dummies. The estimate of (Day 30 - 29)*LOS was positive and the daily expenditures did not decrease after the specific hospitalization period. The daily expenditure decreased by 5.7\% after the 2010 revision and it was much larger than that of the ALOS.

The medical expenditures for educational hospitalization of patients with diabetes were heavily dependent on ALOS. Therefore, to control medical expenditures, it will be necessary to reduce ALOS. This could be done by introducing a critical path, and by improving and standardizing educational programs, especially in hospitals with long ALOS. By taking these steps, it might be possible to reduce the medical expenditures for educational hospitalization significantly without any degradation to the effects of hospitalization. For the Japanese medical payment system, incentives to hospitals to improve their efficiencies (reducing costs without degrading the quality of medication) are very important. However, desirable incentives specific to various diseases have not been determined. These are subjects to be studied in the future.

\section{Acknowledgements}

This study was supported by a Grant-in-Aid for Scientific Research on the subject of "Analyses of Large Scale Medical Survey Data and the Policy Evaluations in Japan (Grant Number: 24330067),” from the Japan Society of Science. The Institutional Review Boards of the University of Tokyo (number: KE12-7) and Tokyo Medical and Dental University (number: 839) approved the use of this dataset. We would like to thank an anonymous referee for his/her helpful comments and suggestions. 


\section{References}

[1] Ministry of Health, Lobour and Welfare (2014) Heisei 24 nendo kokumun iryouhi no gaikyou (Summary of National Medical Expenditures in Fiscal Year 2012). (In Japanese)

[2] World Health Organization (WHO) (2015) Global Health Expenditure Database. http://apps.who.int/nha/database

[3] Statistics Bureau, Ministry of Internal Affairs and Communications (2015) Population and Percentage Distribution by Age (5-Year Age Group) and Sex. (In Japanese)

[4] Chang, S., He, Y. and Hsieh, C. (2014) The Determinants of Health Care Expenditure toward the End of Life: Evidence from Taiwan. Health Economics, 23, 951-961. http://dx.doi.org/10.1002/hec.2970

[5] de Mello-Sampayo, F. and de Sousa-Vale, S. (2014) Financing Health Care Expenditure in the OECD Countries: Evidence from a Heterogeneous, Cross-Sectional Dependent Panel. Panoeconomicus, 61, 207-225. http://dx.doi.org/10.2298/PAN1402207M

[6] Geue, C., Briggs, A., Lewsey, J. and Lorgelly, P. (2014) Population Ageing and Healthcare Expenditure Projections: New Evidence from a Time to Death Approach. European Journal of Health Economics, 15, 885-896. http://dx.doi.org/10.1007/s10198-013-0543-7

[7] Gregersen, F.A. (2014) The Impact of Ageing on Health Care Expenditures: A Study of Steepening. European Journal of Health Economics, 15, 979-989. http://dx.doi.org/10.1007/s10198-013-0541-9

[8] Hartwig, J. and Sturm, J. (2014) Robust Determinants of Health Care Expenditure Growth. Applied Economics, 46, 4455-4474. http://dx.doi.org/10.1080/00036846.2014.964829

[9] Lau, C.K.M., Fung, K.W.T. and Pugalis, L. (2014) Is Health Care Expenditure across Europe Converging? Findings from the Application of a Nonlinear Panel Unit Root Test. Eurasian Business Review, 4, 137-156. http://dx.doi.org/10.1007/s40821-014-0014-9

[10] Lopez-Casasnovas, G., Maynou, L. and Saez, M. (2015) Another Look at the Comparisons of the Health Systems Expenditure Indicators. Social Indicators Research, 121, 149-175. http://dx.doi.org/10.1007/s11205-014-0628-4

[11] Schubert, S. (2014) Reducing Public Health Insurance Expenditure: A Numerical Analysis for Germany. Applied Economics, 46, 2228-2241. http://dx.doi.org/10.1080/00036846.2014.896982

[12] Villaverde, J., Maza, A. and Hierro, M. (2014) Health Care Expenditure Disparities in the European Union and Underlying Factors: A Distribution Dynamics Approach. International Journal of Health Care Finance and Economics, 14, 251-268. http://dx.doi.org/10.1007/s10754-014-9147-8

[13] Wu, P., Liu, S. and Pan, S. (2014) Nonlinear Relationship between Health Care Expenditure and Its Determinants: A Panel Smooth Transition Regression Model. Empirica, 41, 713-729. http://dx.doi.org/10.1007/s10663-013-9233-z

[14] Organization for Economic Cooperation and Development (OECD) (2015) Health Statistics. http://www.oecd.org/els/health-systems/health-data.htm

[15] Ministry of Health, Labour and Welfare (2013) Heisei 24 nen iryoushisetsiu (doutai) chousa/byouin houkoku no Gaiyou [Summary of Medical Facility (State) Surveys and Hospital Reports in 2012]. (In Japanese)

[16] American Diabetes Association (ADA) (2013) Economic Costs of Diabetes in the US in 2012. Diabetes Care, 36, 1033-1046. http://dx.doi.org/10.2337/dc12-2625

[17] ADA (2015) Statistics about Diabetes. http://www.diabetes.org/diabetes-basics/statistics/?loc=db-slabna

[18] OECD (2012) Health: The High Cost of Diabetes. http://www.oecd.org/newsroom/healththehighcostofdiabetes.htm

[19] International Diabetes Foundation (IDF) (2014) Diabetes Atlas Sixth Edition. http://www.idf.org/sites/default/files/Atlas-poster-2014_EN.pdf

[20] Ministry of Health, Labour and Welfare (2014) Heisei 25 nendo kokumin eiyou shousa (National Nutrition Survey in FY 2013). (In Japanese)

[21] IDF (2015) About Diabetes. http://www.idf.org/about-diabetes

[22] ADA (2015) Diabetes Basic. http://www.diabetes.org/

[23] ADA (2015) Are You at Risk? http://www.diabetes.org/

[24] IDF (2011) Diabetes Self-Management Education: A Right for All. http://www.idf.org/education/self-management-education

[25] ADA (2015) Food \& Fitness. http://www.diabetes.org/

[26] Diabetes UK (2003) Care Recommendation, Education of People with Diabetes. https://www.diabetes.org.uk/documents/professionals/patient_education.doc

[27] Mehrotra, S. and Kim, K. (2011) Outcome Based State Budget Allocation for Diabetes Prevention Programs Using 
Multi-Criteria Optimization with Robust Weights. Health Care Management Science, 14, 324-337. http://dx.doi.org/10.1007/s10729-011-9166-7

[28] Nelson, K.M., Chapko, M.K. and Reiber, G. (2005) The Association between Health Insurance Coverage and Diabetes Care; Data from the 2000 Behavioral Risk Factor Surveillance System. Health Services Research, 40, 361-372. http://dx.doi.org/10.1111/j.1475-6773.2005.0d362.x

[29] Nawata, K. and Kawabuchi, K. (2015) Evaluation of Length of Hospital Stay Joining Educational Programs for Type 2 Diabetes Mellitus Patients: Can We Control Medical Costs in Japan? Health, 7, 256-269. http://dx.doi.org/10.4236/health.2015.72030

[30] Box, G.E.P. and Cox, D.R. (1964) An Analysis of Transformation. Journal of the Royal Statistical Society B, 26, 211252.

[31] Bickel, P.J. and Doksum, K.A. (1981) An Analysis of Transformations Revisited. Journal of the American Statistical Association, 76, 296-311. http://dx.doi.org/10.1080/01621459.1981.10477649

[32] Nawata, K. (2013) A New Estimator of the Box-Cox Transformation Model Using Moment Conditions. Economics Bulletin, 33, 2287-2297.

[33] Nawata, K. (2015) Robust Estimation Based on the Third-Moment Restriction of the Error Terms for the Box-Cox Transformation Model: An Estimator Consistent under Heteroscedasticity. Economics Bulletin, 3, 1056-1064.

[34] Sato, E. and Fushimi, K. (2009) What Has Influenced Patient Health-Care Expenditures in Japan? Variables of Age, Death, Length of Stay, and Medical Care. Health Economics, 18, 843-853. http://dx.doi.org/10.1002/hec.1410

[35] Younis, M.Z. and Forgione, D.A. (2009) The Relationship between the Balanced Budget Act and Length of Stay for Medicare Patients in US Hospitals. European Journal of Health Economics, 10, 57-63. http://dx.doi.org/10.1007/s10198-008-0103-8

[36] Nagashima, M.M., Ugihara, N., Fukukawa, H., et al. (2005) Comparison of the Effect of a Four-Day and of a Two-Week Educational Hospitalization Using Critical Path on the Control of Diabetes Mellitus. Journal of Japan Society for Health Care Management, 5, 487-492. (In Japanese with English Abstract)

[37] Yamamoto, M., Takeuchi, Y. and Ichiwaka, H. (2000) A Critical-Path of Educational Program for Diabetic Inpatient. Journal of Japan Society for Health Care Management, 1, 130-133. (In Japanese with English Abstract)

[38] Kobori, S., Ichikawa, Y., Kodama, S., et al. (2006) Evaluation of Critical Pathway Computerization of the Educational Hospitalization for Diabetes Mellitus. Journal of Japan Society for Health Care Management, 7, 315-319. (In Japanese with English Abstract)

[39] Turumi, K. (2002) Medical Nutritional Education and Critical Pathway: The Result and Problem of Critical Pathway in Educational Admission for Diabetes Mellitus. Japanese Journal of National Medical Services, 56. 160-161. (In Japanese)

[40] Kopp, D.M. (2006) Trainer Self-Loathing? Human Resource Development Quarterly, 17, 351-357. http://dx.doi.org/10.1002/hrdq.1179

[41] Department of Health and Diabetes UK (2005) Structured Patient Education in Diabetes-Report from the Patient Education Group. http://www.ipcem.org/etp/PDFetp/StructuredReport.pdf

[42] Windrum, P. (2008) Patient-Centered Diabetes Education in the UK. In: Windrum, P. and Koch, P., Eds., Innovation in Public Sector Services: Entrepreneurship, Creativity and Management, Edward Elgar, Cheltenham, 162-185. http://dx.doi.org/10.4337/9781848441545.00017

[43] Nawata, K., Ii, M., Toyama, H. and Takahashi, T. (2009) Evaluation of the Inclusive Payment System Based on the Diagnosis Procedure Combination with Respect to Cataract Operations in Japan-A Comparison of Lengths of Hospital Stay and Medical Payments among Hospitals. Health, 1, 93-103. 


\section{Appendix: Abbreviations}

The following abbreviations were used in this paper.

ADA: The American Diabetes Association.

ALOS: average length of stay.

BC Model: Box-Cox transformation model.

BC MLE: maximum likelihood estimator under the normality assumption for the BC model.

DPC: diagnosis procedure combination (It is unique to Japan and classifies diseases, operations, treatments, and patient conditions using a 14-digit code).

DPC/PDPS: diagnosis procedure combination/per diem payment system (The DPC-based inclusive payment system introduced in 2003).

FY: fiscal year.

GDP: Gross Domestic Product.

ICD-10: International Classification of Diseases version 10.

IDF: International Diabetes Federation.

LOS: length of stay (in hospital).

OECD: Organisation for Economic Cooperation and Development.

OLS: ordinary least squares.

WHO: World Health Organization. 